\title{
BUDGET UAV SYSTEMS FOR THE PROSPECTION OF SMALL- AND MEDIUM- SCALE ARCHAEOLOGICAL SITES
}

\author{
W. Ostrowski ${ }^{\text {a,* }}, \mathrm{K}$. Hanus ${ }^{\text {b, }}$ \\ ${ }^{a}$ Faculty of Geodesy and Cartography, Warsaw University of Technology, 1 Politechniki Sq., 00-661 Warszawa, \\ Poland - w.ostrowski@gik.pw.edu.pl

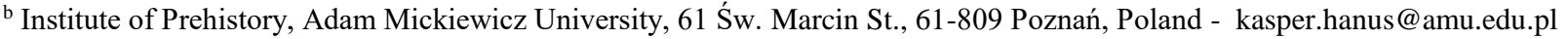

\author{
Commission I, ICWG I/Vb
}

KEY WORDS: Archaeology, Photogrammetry, UAV, UAS, Unmanned Aerial Vehicles, Platforms, Mission Planning, Mapping

\begin{abstract}
:
One of the popular uses of UAVs in photogrammetry is providing an archaeological documentation. A wide offer of low-cost (consumer) grade UAVs, as well as the popularity of user-friendly photogrammetric software allowing obtaining satisfying results, contribute to facilitating the process of preparing documentation for small archaeological sites. However, using solutions of this kind is much more problematic for larger areas. The limited possibilities of autonomous flight makes it significantly harder to obtain data for areas too large to be covered during a single mission. Moreover, sometimes the platforms used are not equipped with telemetry systems, which makes navigating and guaranteeing a similar quality of data during separate flights difficult. The simplest solution is using a better UAV, however the cost of devices of such type often exceeds the financial capabilities of archaeological expeditions.

The aim of this article is to present methodology allowing obtaining data for medium scale areas using only a basic UAV. The proposed methodology assumes using a simple multirotor, not equipped with any flight planning system or telemetry. Navigating of the platform is based solely on live-view images sent from the camera attached to the UAV. The presented survey was carried out using a simple GoPro camera which, from the perspective of photogrammetric use, was not the optimal configuration due to the fish eye geometry of the camera. Another limitation is the actual operational range of UAVs which in the case of cheaper systems, rarely exceeds 1 kilometre and is in fact often much smaller. Therefore the surveyed area must be divided into sub-blocks which correspond to the range of the drone. It is inconvenient since the blocks must overlap, so that they will later be merged during their processing. This increases the length of required flights as well as the computing power necessary to process a greater number of images.
\end{abstract}

These issues make prospection highly inconvenient, but not impossible. Our paper presents our experiences through two case studies: surveys conducted in Nepal under the aegis of UNESCO, and works carried out as a part of a Polish archaeological expedition in Cyprus, which both prove that the proposed methodology allows obtaining satisfying results. The article is an important voice in the ongoing debate between commercial and academic archaeologists who discuss the balance between the required standards of conducting archaeological works and economic capabilities of archaeological missions.

\section{INTRODUCTION AND RESEARCH ISSUE}

Since the beginning of the second decade of 21 th century UAV became essential component in archaeological tool-box. Images made by drones are categorized as "Low Altitude Aerial Photos" (LAAP). Archaeologists have been using LAAP for over a century but only very few specialists could benefit from this kind of data as the available flying platforms like blimps or kites demanded a lot of training, were very weather-dependent and often unreliable (Verhoeven, 2009). But as soon as easier to operate UAV systems became available the number of research using LAAP significantly increased (Campana, 2016). Less expensive UAV systems allow to make oblique images that represents relations between archaeological sites and surrounding landscapes. Together with more and more userfriendly photogrammetric software they make it possible to create 3D models of excavations, architecture and sites (eg. Dell'Unto et al. 2015).
The main application for UAVs (mainly multicopters which are cheaper and easier to use than fixed-wing systems) in archaeology is for low-scale excavation research or mapping site and its surroundings (numerous examples can be found in literature e.g. Bendea et al., 2007, Eisenbeiss and Zhang, 2006, Grün et al., 2012, Rinaudo et al., 2012, Fallavollitaa et al. 2013, Themistocleous et al., 2014, Tscharf er al, 2015). Making accurate documentation for excavation sites has a key meaning for methodology of archaeological research. And for that purpose UAV methods may be sometimes better than some other procedures popular in archaeology. Excavations are always destructive because during exploration the latter cultural layers are irretrievably gone. Other destructions are the effect of transformations in modern landscape caused by urbanization processes. Using UAV and photogrammetry is not invasive nor destructive. These methods are also quick and they are accurate in depicting the reality of archaeological site.

\footnotetext{
* Corresponding author
} 
Still low-cost (customer) grade UAV systems have some limitations. It is impossible to make autonomous flights by preprogramming flight paths. Including also weak RC transmitter, this restricts useful range of flight to less than one kilometre (and often only several hundred meters). It is enough for prospection of small areas e.g. individual archaeological site or smaller elements of a landscape. However prospection of areas bigger then square kilometre can be challenging because it is impossible to take all the needed images during a single flight. Obviously, the best solution would be to purchase the kind of equipment that can be adjusted to necessary time of flight and its range. Unfortunately this solution is often impossible due to limited funding of archaeological research.

Therefore the main goal of our research was to introduce new technical solutions and to propose and evaluate methodology that make it possible to examine larger areas and elements of the landscape (more than $1 \mathrm{~km}^{2}$ ) using UAV. If the method prove to be effective it would give access to new documenting tool for wide range of institutions and researchers. Since most of European archaeological research are rescue excavations, made prior to the construction works, their economic result is significant and introducing cheap method of gathering accurate data by using UAV will result in saving archaeological heritage which would otherwise be irretrievably lost.

\section{THE METHOD}

Main difficulty that users of simple UAV systems come across during their work is limited range of flight which does not allow to take images necessary for further processing during single flight. The most convenient way of gathering all the essential data is autonomous flight on previously defined path. But for this it would be necessary to have better equipment on archaeological site.

The method we introduce in this paper was designed to document wider areas with using the simplest possible UAV configuration. We decided that it should be a platform that does not demand autonomous flights nor transmitting telemetry. The only available convenience is live transmission from camera (visual navigation). The suggested method includes three stages: planning of a flight, obtaining images and data processing, which we discuss further in these paper.

\subsection{Flight planning}

The first stage of tested method is flight planning. In case of taking images of larger area which cannot be photographed in single flight (nor in two or three complementary flights) the whole area have to be divided into blocks (subareas). Then for each block the plan of a flight have to be made as well as ground control point (GCP). The size of blocks should be carefully considered so it would be possible to take all the flights for one subarea in one single day. Therefore the size is dependent on local conditions (the number of hours of good lighting and clear visibility during a day) and number of batteries available. Additionally a minimum overlap between blocks should be at least one row.

As a basemap for flight planning we use satellite imaging. On this basemap we bring axis of following rows which are necessary to further control of the flight (Fig. 1). While using only visual navigation the area must be divided into blocks in a way that enable effective navigation. For this reason easily identified distinctive objects should serve as the demarcation line of blocks and flight lines should be perpendicular to these objects so it would become easier to maintain on change flight direction.

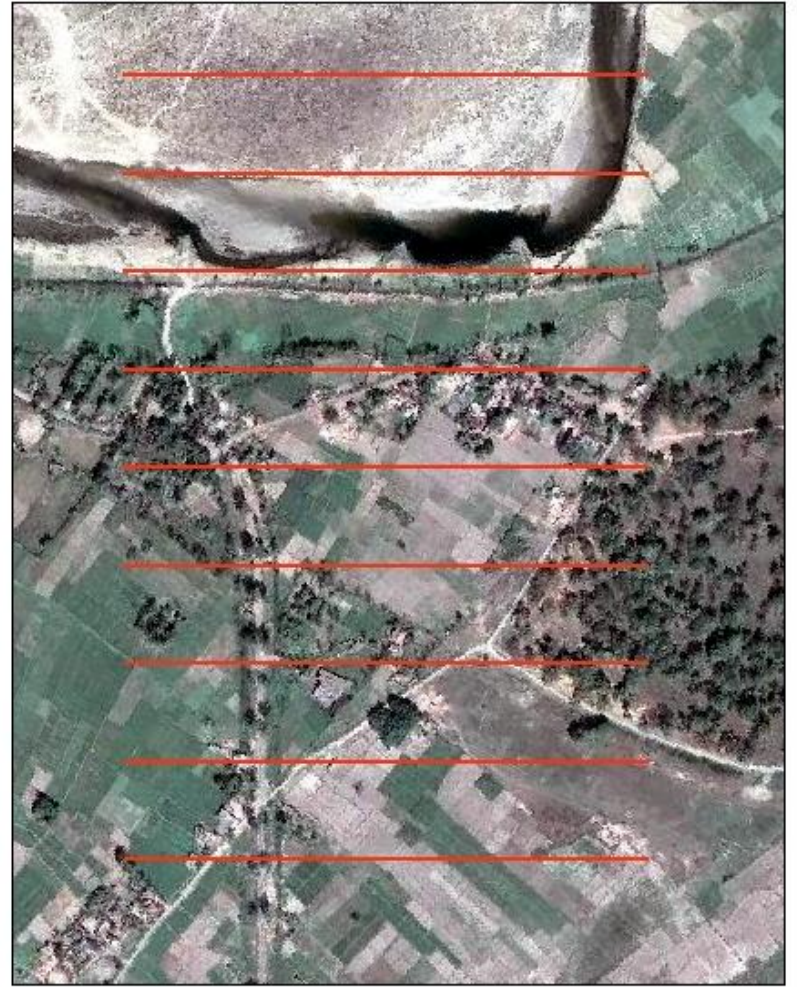

Figure 1. Flight plan. Axis of flight lines are marked red. Available satellite image was used as a basemap.

Another element crucial to planning a flight at this stage are GCPs. Every block should include at least 6 GCPs so it could be independently processed and studied. Due to the overlap between blocks most of the GCPs qualify for use in more than one block. Sharing GCP between blocks also simplify its joining on further stages.

\subsection{Flight mission}

Execution of proper flights is the most difficult and the most important stage. The more simplified UAV system used, the more difficult this task becomes. Previously developed plan of a flight helps to obtain accurate data. Helpful on this stage is making the assumption that side overlap should be $50 \%$. As a result the range of single image covers an area between axis of rows which are next to the one being photographed. This is also suitable solution for visual control of altitude of flight and accurate assessment whether images that are taken have assumed Ground Sampling Distance (GSD). Operating without telemetry, this is the only method to control flight altitude. For that reason it is especially important to choose the right starting point which is suitable to asses flight altitude based on field details.

\subsection{Data Processing}

Finally, all of the obtained data has to be processed using photogrammetric software for acquiring DTM and ortophotomaps needed to document archaeological site. We suggest dividing data processing stage into two steps: pre- 
processing which is made instantly after getting images of every other block and final processing which is done preferably on more powerful computer than the ones we usually use in situ on an archaeological site.

Pre-processing is required to be done instantly so after each block has been photographed. Pre-processing has two main functions. Firstly, it verifies if efficient processing of obtained images can be actually done. Secondly, it gives researchers a chance to evaluate quality of these images. This step is necessary for making initial assessment of images and creating dense points cloud. Through effective assessment researchers can be ensured that images were taken correctly. Settings suitable for these processes depend on the size of blocks (and number of images taken) and available computing power.

The easiest test for initial assessment of quality of data is analysing the density of points cloud, specifically verifying whether the points cloud is evenly dense. The points density parameter together with checking if GSD is not worse than expected should be enough to ensure the acceptable quality of data. Pre-processing on the field is very useful because instantly provides information whether repeating flights for some blocks is necessary if obtained data would not met the expectations.

Furthermore elements of exterior orientation for particular images obtained as a result of pre-processing can be later used during final data processing as initial parameters of exterior orientation (which are usually provided by on-board GPS measurements).

The next step of data processing is providing final products. All of the phots are processing once again and to do it properly a lot of computing power is required which is not always available on a field. Though it may be possible to obtain correct result through processing data separately for every other block and then combining these result (e.g. using GIS environment), the method described in this paper recommends processing all of the data once again in order to produce final product and eliminate the risk of potential systematic errors.

Due to predicted large amount of images that need to be processed it is essential to use information about initial orientation of particular images so the matching process can be considerably shortened. As described above, in a case when researches use simple UAV systems which does not track positions points of every image taken using GPS, on this stage initial parameters of exterior orientation from pre-processing should be used. As for GCPs, their significant amount due to area division into blocks, makes it possible to change some of them into Check Points during final adjustment, which result in efficient monitoring of final outcome.

\section{RESULTS}

The proposed method was tested during research on two archaeological sites: Paphos in Cyprus and Kapilvast in Nepal. Both sites are ancient cities and the size of archaeological landscape being studied by researchers was accordingly $1.1 \mathrm{~km}^{2}$ and $2.9 \mathrm{~km}^{2}$. Both cases also included using cheap custommade UAV which price at the time of purchasing in early 2014 was lower than 3000 USD. The UAV system was based on DJI Naza-M Lite controller which controls the work of six electric engines. Stabilized by gimbal camera was standard action camera GoPro Hero 3 Black Edition.
The UAV system had operational range of approximately 500 meters which was significantly limited when there were some obstacles between an operator and the device, such as trees or buildings. Naza-M Lite controller is equipped with GNSS system supporting flights in "GPS Attitude Mode", but it does not give the opportunity for its users to program specific flight paths. And as in theory engineers of DJI company were trying to create controller which by using GPS data could maintain straight-line flight, unfortunately the system is significantly influenced by meteorological conditions; even slight wind can rotate flying device by a small number of degrees what is especially problematic during reversing flight direction (Fig.2) which result in a distraction to straight-line flight necessary to proper data acquisition. Consequently true range of UAV system was limited and the size of square block that was photographed was maximum 700-800 meters if operator managed to stand in a central point of a block (which was not always possible).

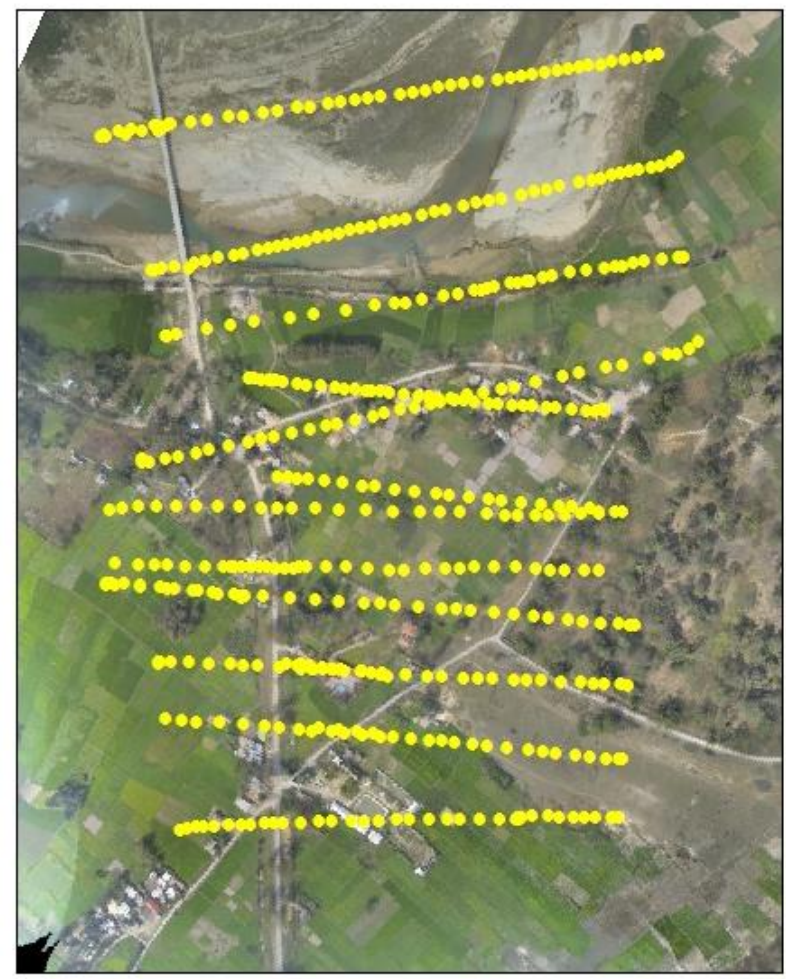

Figure 2. Actual flight (its plan was presented in Figure 1). Two main difficulties can be noticed; the first one (in north part of block) in visual navigation in area where there was a bridge built after acquisition of basemap satellite image and the second in maintaining parallel fight line during reversing flight direction which was caused by the wind.

The GoPro Hero 3 Black Edition camera which was used during research has fish-eye lenses that caused some additional difficulties during data processing. Efficient 3D reconstruction from images obtained with fish-eye lens needs proper geometric model of a camera (Strecha et al. 2015) which is different from pin-hole camera models used in most photogrammetric software.

The camera was placed on 3-axis gimbal stabilizer. Nadir photos were taken and gimbal stabilizer provided almost perpendicular position of the lenses to the ground. GoPro 
camera cannot be remote controlled by radio (the developer allows only connecting the device through wi-fi connection with smartphone or a tablet on short-distance). Therefore the device was programmed before taking off so it took images in $1 / 2 / 5$ second intervals depending on current requirements. Video link was used to receive visuals from camera by operator staying on the ground (but the video link was not connected to the controller so telemetry was not sent directly to operator's screen). Single flight on one set of batteries ( $2 \mathrm{x} \mathrm{LiPo} ; 14.8 \mathrm{~V}$; $5000 \mathrm{mAh}$ ) depending on the weather took 15-20 minutes.

\subsection{Prospection at Kapilvastu, Nepal}

Firstly we examined archaeological site Kapilvast in Lumbini Zone in southern Nepal. This site is identified as Tilaurakot (although it lacks some clear archaeological and historical evidence), the city that Siddhartha Gautama (called Buddha by his followers) lived in for first twenty nine years of his life. For that reason the site becomes more and more popular every year among pilgrims and tourists (Coningham et al. 2014). The development of tourist facilities can be a real threat to archaeological landscape so UNESCO launched interdisciplinary project to create a balanced urban development plan of modern Kapilvastu which guarantee local community economic growth and protects archaeological heritage. Being part of the project, authors of this paper were responsible for making orthophotomaps and DTM which became basemaps for further planning.

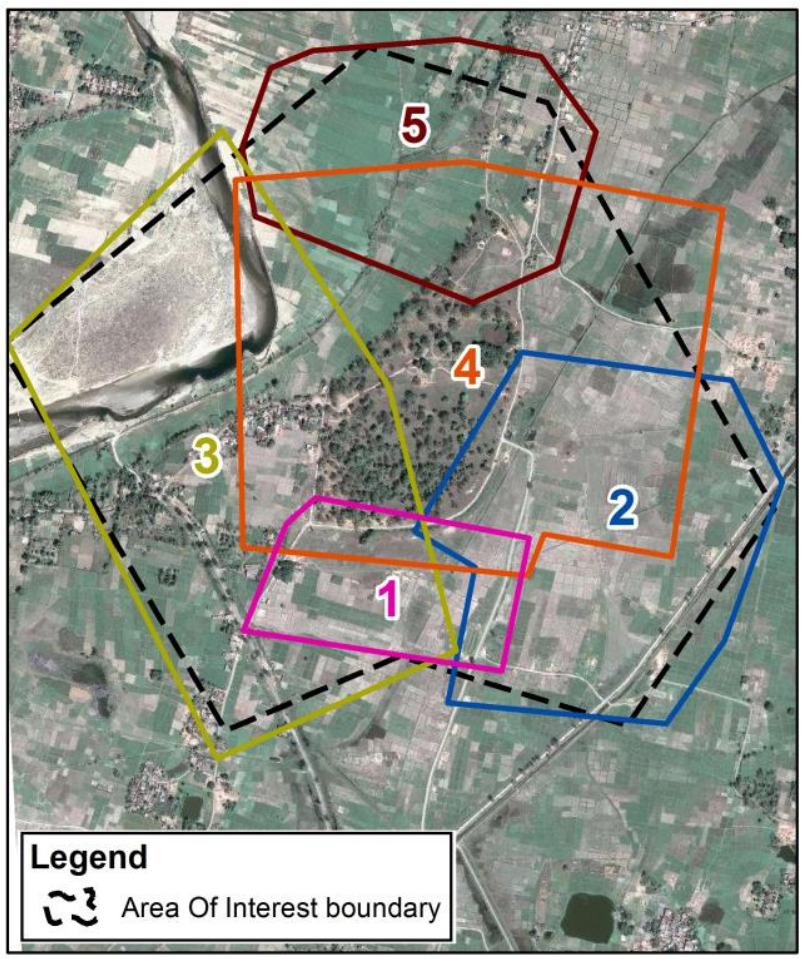

Figure 3. Division of Area of Interest into blocks for Kapilvastu site.

Archeological site covered large area of a landscape $\left(2.9 \mathrm{~km}^{2}\right)$ Archaeological site covered large area of a landscape $\left(2.9 \mathrm{~km}^{2}\right)$ which caused a need to divide it into five blocks (Fig. 3), consisted of about 3000 images (details in Tab. 1). Target resolution of ortophotomap was 10 centimetres, but due to optical properties of a camera it was decided to make flight at lower altitude so that GSD in central part of a photograph was not bigger than 8 centimetres. However weather conditions (vertical visibility) during some flights made reaching planned altitude impossible and final resolution of images was between 4 and 8 centimetres.

\begin{tabular}{|c|c|c|c|c|c|}
\hline Block & Images & $\begin{array}{c}\text { Area } \\
{[\mathrm{ha}]}\end{array}$ & $\begin{array}{c}\text { Mean } \\
\text { GSD [cm] }\end{array}$ & GCP & $\begin{array}{c}\text { Time of } \\
\text { processing }\end{array}$ \\
\hline 1 & 319 & 17.7 & 3.8 & 12 & $1 \mathrm{~h}: 41 \mathrm{~m}$ \\
\hline 2 & 538 & 61.1 & 5.0 & 17 & $1 \mathrm{~h}: 31 \mathrm{~m}$ \\
\hline 3 & 621 & 92.8 & 6.9 & 20 & $2 \mathrm{~h}: 40 \mathrm{~m}$ \\
\hline 4 & 1103 & 115.6 & 4.5 & 24 & $1 \mathrm{~h}: 43 \mathrm{~m}$ \\
\hline 5 & 320 & 43.4 & 5.7 & 9 & $1 \mathrm{~h}: 36 \mathrm{~m}$ \\
\hline Merged & 2901 & 293.1 & 4.9 & 55 & $19 \mathrm{~h}: 54 \mathrm{~m}$ \\
\hline
\end{tabular}

Table 1. Blocks characteristics for Kapilvastu site.

The area was rural therefore only some of the 55 GCPs could be painted on asphalt or other solid surface. The rest was placed in the field on cardboards with painted black and white markers. Position of GCP were measured by total station in local archaeological coordinate system.

The data was processed using Pix4D mapper software. Six of GCPs were used as check points. Additionally the obtained DSM was compared with total station measurements the 87 points measured on exposed hard surface (e.g. roads) were used. The results (Tab. 2) are satisfactory and accuracy of DSM (on exposed hard surface) in comparison to total station measurements is close to accuracy of aerotriangulation.

\begin{tabular}{|c|c|c|c|c|c|c|c|}
\hline Points & \multicolumn{2}{|c|}{$\begin{array}{c}\text { Ground Control } \\
\text { Points [n= 49] }\end{array}$} & \multicolumn{2}{c|}{$\begin{array}{c}\text { Check Points } \\
{[\mathrm{n}=6]}\end{array}$} & $\begin{array}{c}\text { DSM } \\
{[\mathrm{n}=87]}\end{array}$ \\
\hline $\begin{array}{c}\text { Stats } \\
{[\mathrm{cm}]}\end{array}$ & $\mathrm{X}$ & $\mathrm{Y}$ & $\mathrm{Z}$ & $\mathrm{X}$ & $\mathrm{Y}$ & $\mathrm{Z}$ & $\mathrm{Z}$ \\
\hline Mean & 0.1 & 0.2 & 0.6 & 0.4 & 1.4 & -0.6 & -2.5 \\
\hline Std & 2.0 & 2.7 & 3.5 & 5.1 & 7.0 & 4.8 & 9.8 \\
\hline RMSE & 2.0 & 2.7 & 3.6 & 5.1 & 7.2 & 4.9 & 10.2 \\
\hline
\end{tabular}

Table 2. Achieved accuracies for Kapilvastu site.

\subsection{Prospection at Paphos, Cyprus}

Second case study was research in Cyprus on UNESCO World Heritage Site of Paphos as a part of Polish archaeological mission (principal investigator: prof. Ewdoksja PapuciWładyka, leading partner: Institute of Archeology, Jagiellonian University in Krakow, Poland). Ancient Paphos was a capital of Cyprus during Hellenistic period and during Roman Empire. The main goal of Polish archaeological project is to reconstruct urban, social and economic relations in ancient times (PapuciWładyka and Machowski, IN PRESS). Despite excavations and geophysical studies to verify hypothesis about functioning of the city, also prospection using UAV was made. The research was particularly important e.g. for verifying hypothesis about a port in north-west part of the city (Ćwiąkała et al. 2016) where DEM generated from UAV images could prove existence of depression in a surface which could be remains from port basin.

Desired quality of orthophotomaps was higher than in case of Kapilvastu site, target resolution was at least $5 \mathrm{~cm}$. Similar to previous example, images were acquired at lower flight altitude than needed in order to maintain some safety margin. GSD in central part of images was no bigger than $4 \mathrm{~cm}$. Obtaining images with GSD that small required much lower altitude of a 
flight which highly increased number of images. Fortunately area of prospection at Cyprus $\left(1.1 \mathrm{~km}^{2}\right)$ was smaller than in Kapilvastu and was covered with almost 3800 images divided into 6 blocks (Fig 4).

All of 24 GCPs was placed in the field on cardboards with painted black and white markers. Position of GCP were measured by GPS RTK in local archaeological coordinate system.

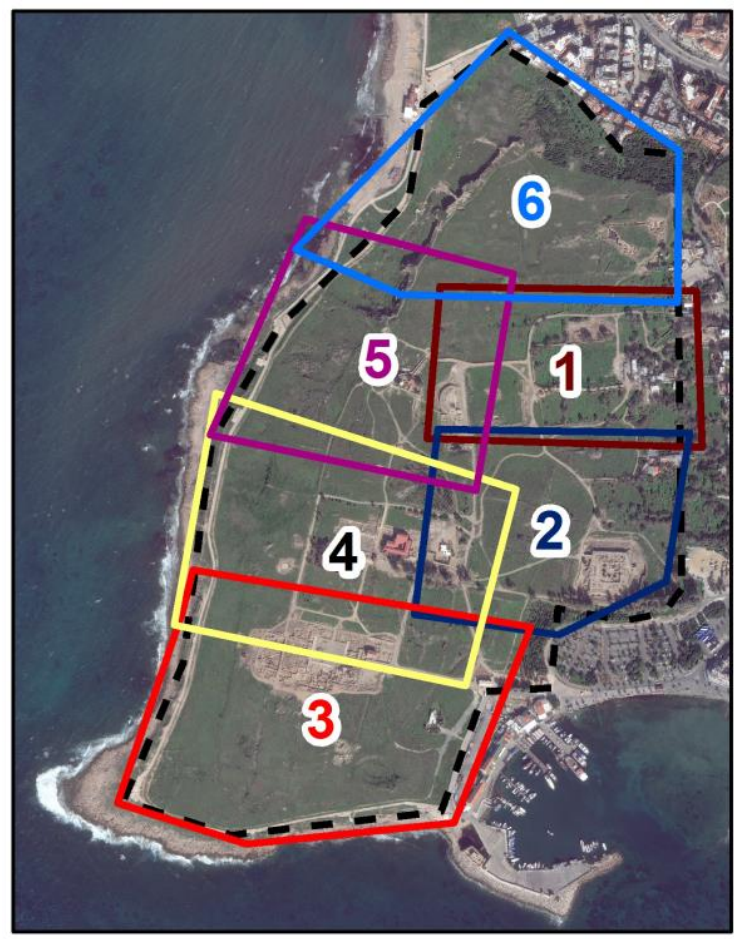

Figure 4. Division of Area of Interest into blocks for Nea Paphos site.

In situ data processing was perform on notebook with Agisoft PhotoScan (details in Tab. 3). Finally data from all merged blocks was processed on a server using Pix4D mapper software.

\begin{tabular}{|c|c|c|c|c|c|}
\hline Block & Images & $\begin{array}{c}\text { Area } \\
{[\mathrm{ha}]}\end{array}$ & $\begin{array}{c}\text { Mean } \\
\text { GSD [cm] }\end{array}$ & GCP & $\begin{array}{c}\text { Time of } \\
\text { processing }\end{array}$ \\
\hline 6 & 1392 & 39.3 & 2.4 & 11 & $5 \mathrm{~h}: 30 \mathrm{~m}$ \\
\hline 5 & 441 & 22.2 & 2.8 & 7 & $35 \mathrm{~m}$ \\
\hline 4 & 407 & 2.10 & 3.1 & 6 & $45 \mathrm{~m}$ \\
\hline 3 & 388 & 21.7 & 2.9 & 4 & $31 \mathrm{~m}$ \\
\hline 2 & 624 & 21.3 & 2.2 & 4 & $1 \mathrm{~h}: 28 \mathrm{~m}$ \\
\hline 1 & 527 & 13.1 & 1.9 & 6 & $1 \mathrm{~h}: 9 \mathrm{~m}$ \\
\hline Merged & 3779 & 110.3 & 3.3 & 24 & $36 \mathrm{~h}: 07 \mathrm{~m}$ \\
\hline
\end{tabular}

Table 3. Blocks characteristics for Nea Paphos site.

For quality control during final processing four GCPs were used as Check Point. Achieved accuracies (Tab. 4) are fully satisfactory although there is no significant improvement, which could be expected because of smaller GSDs, in results obtained on Check Point in comparison to Kapilvastu case.

\begin{tabular}{|c|c|c|c|c|c|c|}
\hline Points & \multicolumn{3}{|c|}{$\begin{array}{c}\text { Ground Control } \\
\text { Points [n=20] }\end{array}$} & \multicolumn{3}{c|}{$\begin{array}{c}\text { Check Points } \\
{[\mathrm{n}=4]}\end{array}$} \\
\hline $\begin{array}{c}\text { Stats } \\
{[\mathrm{cm}]}\end{array}$ & $\mathrm{X}$ & $\mathrm{Y}$ & $\mathrm{Z}$ & $\mathrm{X}$ & $\mathrm{Y}$ & $\mathrm{Z}$ \\
\hline Mean & 0.0 & 0.0 & 0.1 & -4.2 & -1.9 & -3.9 \\
\hline Std & 1.6 & 1.4 & 1.8 & 6.4 & 2.6 & 2.1 \\
\hline RMSE & 1.6 & 1.4 & 1.8 & 7.7 & 3.2 & 4.5 \\
\hline
\end{tabular}

Table 4. Achieved accuracies for Nea Paphos site.

Additional quality control was performed by comparing a point cloud achieved by dense image matching during final processing image processing (in Pix4D) with terrestrial laser scanner measurements. The area covered includes an archaeological remains of the Odeon (theatre) and the Asclepion ruins which are suitable because they are not covered with many vegetation and because of significant differences in height.

For Cloud to Cloud distance computation Cloud Compare software was used. TLS point cloud consists of about 10 million points, mean distance between point cloud is $5 \mathrm{~cm}$ with standard deviation of $5 \mathrm{~cm}$. Distance distribution (Fig. 5) shows no systematic errors and as it is clearly visible most gross errors were caused by vegetation and features which were temporary or too small to be reconstructed with aerial images (like fences).

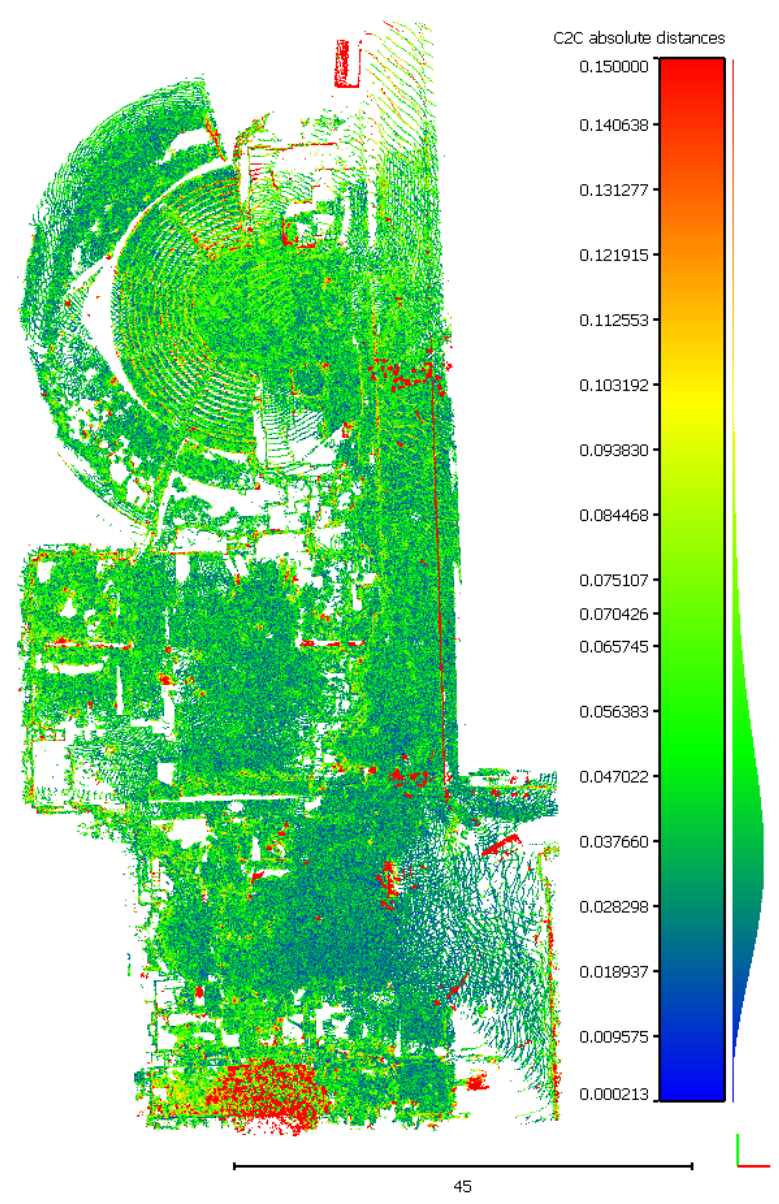

Figure 5. The Odeon and the Asclepion on the Nea Paphos Site. Distances between point clouds from Terrestrial Laser Scanner and dense matching of aerial images. 


\section{DISCUSSION AND CONCLUSIONS}

Both cases proved our pipeline to be effective. It is possible to obtain accurate data and its instant control using cheap UAV system with limited flight range if the method of dividing area into smaller subareas is applied. Despite limited navigation opportunities it was possible to make proper flights for further photogrammetric analysis.

From archaeological perspective the results are very interesting because they prove that even institutions which are equipped with cheaper UAV systems are still able to study landscapes and areas larger than $1 \mathrm{~km} 2$. This leads to democratization of modern technologies which become available to wider group of researchers, including those involved in academic archaeology and leading issue-oriented studies (e.g. research in Cyprus) as well as those involved in heritage management and protecting of archaeological remains in natural landscape (e.g. research in Nepal).

On the other hand, due to intensive development of consumer UAV market (eg. Just lunched DJI Phantom 4) and its application in photogrammetry in the near future many elements of the method discussed in this paper will not be necessary to document larger areas. It is worth mentioning that rapid development of new solutions for autonomous flights like cheap UAV Pix4D application called Capture shall contribute in providing solutions for landscape scale prospection. The research presented above clearly shows that the main struggles were caused by poor-quality flying devices (not with photogrammetric software) and the development in that field will "fill the gap".

\section{ACKNOWLEDGEMENTS}

The authors would like to thank following people and institutions for their support which was necessary to achieve the results discussed in this paper. The research in Nepal was financed by The Japanese-Funds-in-Trust for UNESCO. We would like to acknowledge the help from Mr Kosh Prasad Acharya, prof. Robin Coningham, Sri Acharya Karma Sangbo Sherpa, Mr Ajitman Tamang and the Lumbini Development Trust, UNESCO Kathmandu Office, the Department of Archaeology (Government of Nepal), Durham University, Mr Ram Prasad Pandey, the Risshon Shanti Vihar. Prospection in Cyprus was financed by National Science Centre, Poland (Maestro grant no. 2014/14/A/HS 3/00283) and was possible thanks to prof. Ewdoksia Papuci-Władyka and Mr Łukasz Miszk.

\section{REFERENCES}

Bendea, H., Chiabrando, F., Giulio Tonolo, F., \& Marenchino, D., 2007, October. Mapping of archaeological areas using a low-cost UAV. The Augusta Bagiennorum test site. In XXI International CIPA Symposium pp. 01-06.

Campana, S. 2016. Expanding the Boundaries of Aerial Archaeology: from Balloons to Drones. 2nd International Conference of Aerial Archaeology: From Aerostats to Drones: Aerial Imagery in Archaeology, 3-5 February 2016 Rome

Coningham, R.A.E., Acharya, K. P. and Manuel, M. J. 2014. Strengthening the Conservation and Management of Lumbini, the Birthplace of the Lord Buddha, World Heritage Property
(Phase II): Final Report of the First (Jan-Feb 2014) Season of Field Activities. Kathmandu: UNESCO.

Ćwiąkała P., Hanus, K. J., Matwij K., Matwij W., Miszk Ł., Ostrowski W. 2016. Looking for the lost harbour. Role of noninvasive archaeological methods in the reconstruction of the seascape of an ancient city Paphos. CAA 2016 Exploring Oceans of Data 29 March-2 April 2016, Oslo.

Dell'Unto, N., Landeschi, G., Leander Touati, A. M., Dellepiane, M., Callieri, M., \& Ferdani, D. 2015. Experiencing Ancient Buildings from a 3D GIS Perspective: a Case Drawn from the Swedish Pompeii Project. Journal of archaeological method and theory.

Eisenbeiss, H., \& Zhang, L, 2006. Comparison of DSMs generated from mini UAV imagery and terrestrial laser scanner in a cultural heritage application. International Archives of Photogrammetry, Remote Sensing and Spatial Information Sciences XXXVI-5, pp. 90-96.

Fallavollitaa, P., Balsia, M., Espositoa, S., Melisb, M. G., Milaneseb, M., Zappinoc, L.. 2013. UAS For Archaeology . New Perspectives On Aerial Documentation. International Archives of the Photogrammetry, Remote Sensing and Spatial Information Sciences, XL(September), 4-6.

Grün, A., Zhang, Z., \& Eisenbeiss, H., 2012. UAV photogrammetry in remote areas-3D modeling of Drapham Dzong, Bhutan. International Archives of Photogrammetry, Remote Sensing and Spatial Information Sciences, 39, B1.

Papuci-Władyka E., Machowski, W. IN PRESS. "Paphos Agora Project. Preliminary results of the 2011-2012 seasons of the Jagiellonian University (Krakow, Poland) excavations". In C. Balandier and E. Raptou (eds), Nea Paphos, Fondation et développement urbain d'une ville chypriote de l'antiquité à nos jours. Études archéologiques, historiques et patrimoniales. (Colloque international, Université d'Avignon 2012), Ausonius, Bordeaux.

Rinaudo, F., Chiabrando, F., Lingua, A. M., \& Spanò, A. T., 2012. Archaeological site monitoring: UAV photogrammetry can be an answer. International Archives of Photogrammetry, Remote Sensing and Spatial Information Sciences, 39(B5), pp. 583-588.

Strecha, C., Zoller, R., Rutishauser, S., Brot, B., SchneiderZapp, K., Chovancova, V., Glassey, L. 2015. Quality Assessment of 3d Reconstruction Using Fisheye and Perspective Sensors. ISPRS Annals of the Photogrammetry, Remote Sensing and Spatial Information Sciences, 2(3), 215

Themistocleous, K., Agapiou, A., King, H. M., King, N., \& Hadjimitsis, D. G. 2014. More Than a Flight: The Extensive Contributions of UAV Flights to Archaeological Research-The Case Study of Curium Site in Cyprus. In Digital Heritage. Progress in Cultural Heritage: Documentation, Preservation, and Protection (pp. 396-409). Springer International Publishing.

Tscharf, A., Rumpler, M., Fraundorfer, F., Mayer, G., \& Bischof, H. (2015). On The Use Of UAVs In Mining And Archaeology - Geo-Accurate 3d. ISPRS Annals of the Photogrammetry, Remote Sensing and Spatial Information Sciences, II, 15-22. http://doi.org/10.5194/isprsannals-II-1-W115-2015 
Verhoeven, G. J., 2009. Providing an archaeological bird's-eye view-an overall picture of ground-based means to execute low-altitude aerial photography (LAAP) in Archaeology. Archaeological Prospection, 16(4), pp. 233-249. 